\title{
SIMULASI NUMERIK PENGARUH VARIASI RASIO PANJANG LEADING EDGE TERHADAP KARAKTERISTIK AERODINAMIKA PADA MOBIL PICK UP
}

\author{
Md. Ranasandhya Amy Pratyaksa \\ Teknik Mesin, Fakultas Teknik, Universitas Negeri Surabaya \\ md.pratyaksa@mhs.unesa.ac.id
}

\begin{abstract}
Abstrak - Gaya aerodinamika berpengaruh terhadap konsumsi bahan bakar akibat drag serta stabilitas laju kendaraan karena gaya lift. Memvariasikan geometri pada bagian leading edge di perkirakan memiliki pengaruh terhadap aerodinamika. Penelitian ini, menggunakan model kendaraan pick up dengan dimensi seperti ukuran sebenarnya. Geometri leading edge dimodifikasi sehingga di dapat variasi nilai rasio panjang leading edge terhadap panjang keseluruhan kendaraan $\left(\frac{l_{-1}}{l}\right): \frac{1}{30} ; \frac{1}{13}$ dan $\frac{1}{9}$. Metode penelitian yang digunakan adalah simulasi numerik 2-D pada kondisi steady dan unsteady menggunakan software ANSYS FLUENT 2019 R3. Mesh yang digunakan model Hybrid, berbentuk segitiga dan persegi empat. Model viskos yang digunakan k-epsilon Realizable dengan variasi Reynolds Number 7,15 x 104; 2,6 x 106 $; 3,26$ $\times 10^{6}$ dan 3,91 x $10^{6}$. Data hasil yang dianalisa adalah koefisien lift $\left(C_{L}\right)$, koefisien drag $\left(C_{D}\right)$, velocity contour, velocity streamline, dan pressure contour. Dari hasil simulasi, memvariasikan rasio panjang leading edge dapat mempengaruhi karakteristik aerodinamika pada mobil pick up. Semakin besar rasio leading edge dapat menunda terjadinya separasi di atas mobil pick up. Selain itu defisit momentum di belakang kendaraan juga semakin kecil. Variasi rasio panjang leading edge $\frac{1}{9}$ merupakan variasi terbaik, memiliki nilai koefisien drag $\left(C_{D}\right)$ sebesar 0,72 dengan persentase penurunan $4 \%$ serta koefisien lift $\left(C_{L}\right)$ sebesar 0,07 dengan persentase penurunan $36,36 \%$ dari variasi standar. Nilai $C_{D}$ dan $C_{L}$ turun menjadikan konsumsi bahan bakar lebih efisien dan mobil lebih stabil.
\end{abstract}

Kata Kunci-Simulasi Numerik; Leading Edge; Karakteristik Aerodinamika; Pick Up

Abstract-The aerodynamic style influences fuel consumption due to drag and the stability of the vehicle speed due to the force lift. Varying the geometry of the leading edge is estimated to have an effect on aerodynamics. This study uses a car pickup model with dimensions like the actual size. Geometry Leading Edge can be modified so that in the variation of the ratio of length leading edge of the vehicle's overall length $\left(\frac{L_{1}}{1}\right): \frac{1}{30} ; \frac{1}{13}$ dan $\frac{1}{9}$. The research method used is a 2-D numerical simulation underconditions steady and unsteady using software ANSYS FLUENT 2019 R3. The mesh using Hybrid model, its triangular and rectangular shape. The viscous model used by $k$-epsilon Realizable with variation Reynolds Number $7.15 \times 10^{4} ; 2.6 \times 10^{6} ; 3.26 \times$ $10^{6}$ and $3.91 \times 10^{6}$. The result data analyzed are coefficient lift $\left(C_{L}\right)$, coefficient drag $\left(C_{D}\right)$, velocity contour, velocity streamline, and pressure contour. From the simulation results, varying ratio of the length of leading edge can affect aerodynamic characteristics of the car. The greater leading edge ratio can delay separation above the car. In addition, the momentum deficit behind the vehicle is also getting smaller. Variation of the length ratio of leading edge $\frac{1}{9}$ is the best variation, having a coefficient drag $\left(C_{D}\right)$ of 0.72 with a percentage decrease of $4 \%$ and a coefficient lift $(C L)$ of 0.07 with a reduction percentage of $36.36 \%$ of the standard variation. $C_{D}$ and $C_{L}$ values go down making fuel consumption more efficient and the car more stable.

Kata Kunci-Numerical Simulation; Leading Edge; Aerodynamic Characteristics; Pick Up.

\section{PENDAHULUAN}

Pertumbuhan ekonomi Indonesia yang terus meningkat, tak luput dari peranan di sektor industri khususnya Usaha Mikro, Kecil dan Menengah (UMKM). Keadaan tersebut membuat permintaan mobil khususnya mobil pick up juga mengalami peningkatan. Selain itu, maraknya pengiriman barang melalui aplikasi online turut menambah angka penjualan mobil pick up.
Seiring dengan permintaan pasar mobil global yang terus meningkat, membuat produsen-produsen mobil terus berinovasi dalam mengembangkan produknya agar konsumsi bahan bakar semakin efisien serta aman dan nyaman untuk dikendarai. Dewasa ini, penelitian dalam meningkatkan efisiensi konsumsi bahan bakar tidak hanya dilakukan pada sektor mesin saja namun juga pada bentuk bodi mobil yang berpengaruh terhadap gaya aerodinamika mobil. 
Gaya Aerodinamika dapat mempengaruhi konsumsi bahan bakar karena setiap kendaraan memiliki gaya drag. Gaya drag di harapkan bernilai kecil karena menurut Wailanduw (2005), Koefisien drag yang dimiliki suatu kendaraan mempunyai pengaruh pada aspek ekonomi bahan bakarnya. Artinya, pemanfaatan energi yang di hasilkan dari pembakaran bahan bakar dan udara tidak sepenuhnya dapat digunakan untuk menggerakkan kendaraan tetapi juga harus digunakan untuk mengatasi tahanan angin yang diterima kendaraan saat berjalan. Hucho and Sovran (1993) berpendapat bahwa gaya drag berkontribusi hingga 50\% dari total konsumsi bahan bakar kendaraan pada kecepatan tinggi. Oleh karena itu diharapkan harga koefisien ini tidak besar agar dapat diperoleh pemanfaatan bahan bakar yang semaksimal mungkin.

Menurut Surya (2014) bentuk bodi kendaraan sangat berpengaruh terhadap laju kendaraan dalam menembus aliran fluida. Aliran fluida tersebut memiliki peranan penting dalam menunjang keamanan serta kenyamanan dalam berkendara sehingga perlu diperhatikan. Karena pada gaya aerodinamika juga terdapat gaya lift yang berpengaruh terhadap stabilitas kendaraan.

Terkait dengan pengaruh gaya aerodinamika terhadap efisiensi serta stabilitas laju kendaraan, terdapat banyak cara yang dapat dilakukan untuk memperbaiki karakteristik aerodinamika yang melewati kendaraan. Misalnya dengan memodifikasi bentuk leading edge, menambah roof spoiler, rear spoiler, side skirt, merendahkan tinggi mobil serta mengubah bentuk diffuser. Pada penelitian ini akan dilakukan perubahan bentuk leading edge, dengan memodifikasi panjang leading edge mobil pick up. Karena leading edge merupakan bagian kendaraan yang pertama kali bertabrakan dengan aliran angin. Menurut Surya (2014) bentuk bagian depan kendaraan yang dapat mengalirkan udara secara sempurna akan membuat laju kendaraan lebih stabil, selain itu juga mempengaruhi performa laju kendaraan serta efisiensi terhadap konsumsi bahan bakar. Karena bentuk leading edge juga mempengaruhi pola aliran dibelakang kendaraan yang berdampak pada performa aerodinamika kendaraan.

Karakteristik aerodinamika dari suatu kendaraan dapat diketahui dengan menggunakan berbagai cara. Menurut Katz (2006) penganalisaan data dibedakan menjadi 3 metode yaitu: pengujian wind tunnel (terowongan angin), simulasi menggunakan software berbasis Computational Fluid Dynamics (CFD), dan yang terakhir pengujian di jalan (road test).

Model pengujian Aerodinamika dengan menggunakan metode CFD dinilai lebih fleksibel dan efektif apabila di bandingkan dengan metode eksperimen maupun road test. Biaya yang harus di keluarkan apabila menggunakan model komputasi relatif lebih rendah serta dari segi waktu lebih singkat. Sehingga penggunaan metode CFD jauh lebih unggul daripada metode eksperimen maupun road test.

Perlu diketahui bahwa dengan memodifikasi panjang leading edge mobil pick up akan menghasilkan sudut kap mesin yang berbeda sehingga diduga akan berpengaruh terhadap karakteristik aerodinamika di sekitar kendaraan.
Untuk mengetahui performa aerodinamika kendaraan maka dilakukan simulasi untuk melihat velocity contour, velocity streamline, pressure contour, serta mendapatkan nilai koefisien lift $\left(C_{V_{n}}\right)$ dan koefisien drag $\left(C_{n}\right)$ menggunakan software Ansys Fluent 2019 R3. Simulasi dilakukan pada mobil pick up Daihatsu Gran Max dengan memodifikasi rasio panjang leading edge.

\section{METODE}

\section{A. Jenis Penelitian}

Penelitian yang dilakukan adalah simulasi numerik untuk mengetahui karakteristik aerodinamika dan pengaruh variasi rasio panjang leading edge pada mobil pick up.

\section{B. Variabel Penelitian}

\section{1) Variabel Bebas}

- model kendaraan menyerupai Daihatsu Gran Max dengan variasi rasio panjang leading edge dan panjang kendaraan yaitu $\frac{1}{9} ; \frac{1}{13} ; \frac{1}{30}$.

- Variasi Reynolds number yang digunakan adalah 7,15 x $10^{4} ; 2,6 \times 10^{6} ; 3,26 \times 10^{6} ; 3,91 \times 10^{6}$

\section{2) Variabel Terikat}

Pada penelitian ini adalah : Koefisien Lift $\left(\mathrm{C}_{\mathrm{L}}\right)$, Koefisien Drag $\left(\mathrm{C}_{\mathrm{D}}\right)$, Velocity contour, Velocity streamline dan Pressure contour model kendaraan menyerupai pick up.

\section{3) Variabel Kontrol}

- Dimensi Kendaraan:

$$
\begin{array}{lll}
\text { Panjang (l) } & : 4.190 \mathrm{~mm} \\
\text { Lebar } & \text { (w) } & : 1.675 \mathrm{~mm} \\
\text { Tinggi } & \text { (h) } & : 1.830 \mathrm{~mm}
\end{array}
$$

- Kecepatan pada dinding $=0$

- Temperatur udara $=27^{\circ} \mathrm{C}$

\section{Teknik Pengumpulan Data}

\section{1) Tahap Pre-processing:}

Tahap ini merupakan tahap awal dalam membuat dan menganalisa sebuah model dengan menggunakan metode CFD. Dalam tahap ini dibagi menjadi beberapa sub-tahapan yaitu:

- Pembuatan Geometri

Pembuatan geometri kendaraan menyerupai pick up menggunakan software Solidworks.

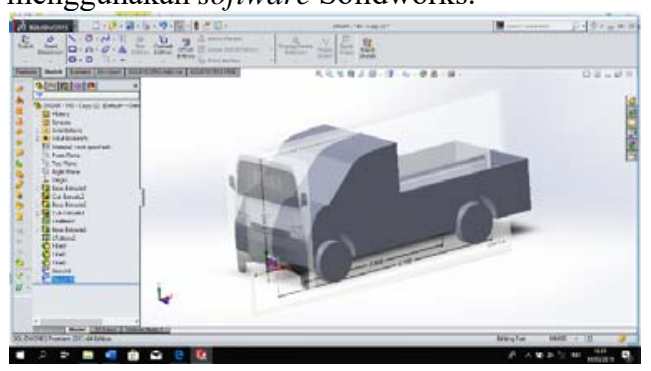

Gbr. 1 Pembuatan Geometri. 
- Pembuatan Domain

Pada tahap pembuatan domain menggunakan software ANSYS Design Modeler, dengan mengimport geometri yang dibuat pada tahap pembuatan geometri. Dibuat sebuah virtual wind tunnel dalam domain yang dimaksudkan untuk menggambarkan keadaan fluida disekitar objek penelitian. Dimensinya mengacu pada penelitian Mustafa (2018) seperti gambar 2.

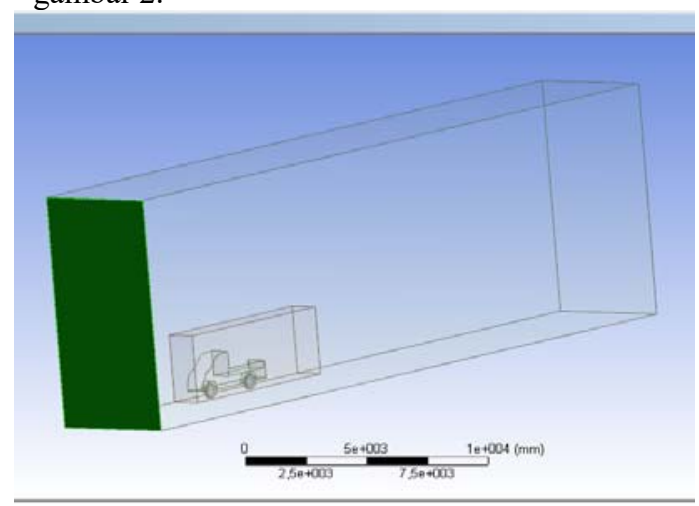

Gbr. 2 Proses Pembuatan Domain.

- Pembuatan Meshing

Proses pembuatan mesh dilakukan dengan menggunakan program ANSYS meshing. Mesh yang digunakan berbentuk segitiga, dimana tipe mesh tersebut mudah untuk menyesuaikan pada bentuk geometri yang kompleks. Pada bagian dekat bodi meshing berbentuk segi empat untuk menyesuaikan bentuk bodi.

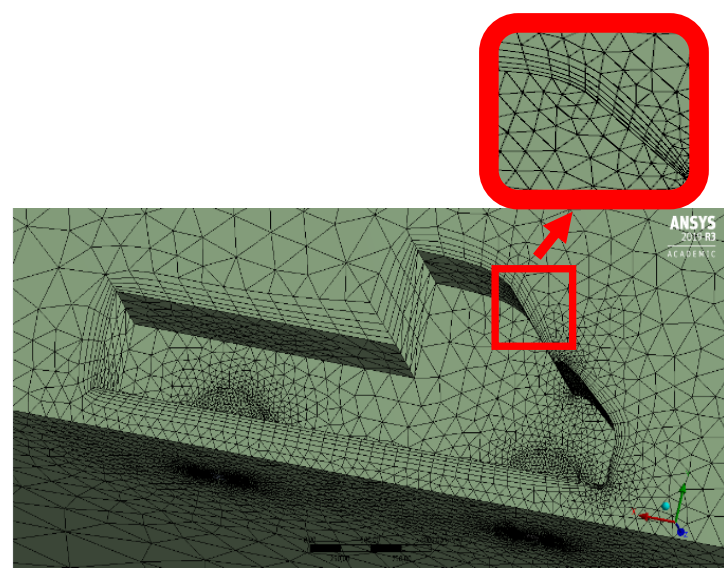

Gbr. 3 Pembuatan Meshing.

\section{- Solver Setting}

Solver setting mencakup beberapa parameter seperti tipe solver (2D atau 3D). Viscous model yang digunakan adalah k-epsilon Realizable. Pada boundary condition, inlet dari virtual wind tunnel digambarkan dengan "velocity inlet", sedangkan outlet dari virtual wind tunnel digambarkan dengan pressure outlet.

\section{2) Tahap Processing:}

Pada tahapan processing, semua kondisi yang sudah ditetapkan di tahap sebelumnya akan dilakukaan perhitungan (iterasi). Pada tahap iterasi, diharapkan tercapai hasil yang konvergen, jika pada tahap iterasi ini belum tercapai hasil yang konvergen maka mesh perlu diperbaiki, atau kembali ketahap meshing untuk memperbaiki mesh. Namun jika hasil yang didapat adalah konvergen, maka dapat melanjutkan ke tahap selanjutnya yaitu tahap post-processing.

\section{3) Tahap Post-processing:}

Pada tahap ini hasil dari perhitungan (iterasi) yang telah dilakukan di tahap sebelumya (processing) ditampilkan berupa data kualitatif dan data kuantitatif. Data kuantitatif berupa data distribusi Koefisien drag dan Koefisien lift. Kemudian data yang bersifat kualitatif ditampilkan secara visualisasi antara lain Velocity contour, Velocity streamlines, dan Pressure contour.

\section{4) Flowchart Penelitian}

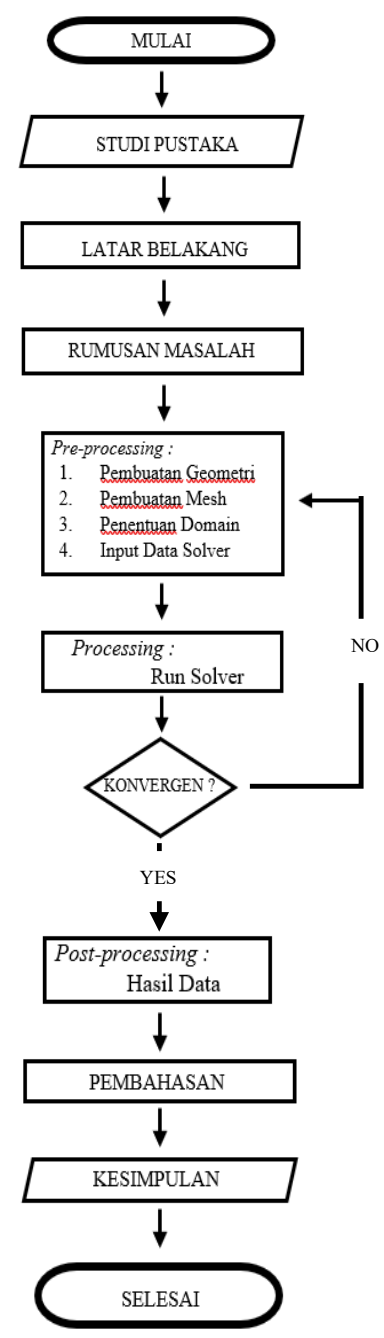

Gbr. 4 Flowcat Penelitian 


\section{HASIL DAN DISKUSI}

\section{A. Validasi Model}

Pada proses validasi, akan dibandingkan data antara hasil simulasi CFD dengan data hasil eksperimen yaitu nilai Koefisien Drag $\left(\mathrm{C}_{\mathrm{D}}\right)$ yang mana memiliki persentase nilai error terendah serta bentuk tren grafik Koefisien pressure $\left(\mathrm{C}_{\mathrm{P}}\right)$. Simulasi CFD menggunakan model viscous k-epsilon standard, k-epsilon Realizable, k-epsilon RNG, k-omega standard, dan k-omega SST. Serta dilakukan uji Grid Independency untuk mendapatkan komposisi terbaik.

\section{1) Persentase Nilai error $C_{D}$}

\section{TABEL I}

VALIDASI MODEL VISKOS

\begin{tabular}{|c|c|c|c|}
\hline \multirow{2}{*}{ No. } & \multirow{2}{*}{ Penelitian } & \multicolumn{2}{|c|}{$\operatorname{Re~7,15~} \mathbf{1 0} \mathbf{1 0}^{\mathbf{4}}$} \\
\cline { 3 - 4 } & & $\mathbf{C D} / \mathbf{C D P}$ & Error (\%) \\
\hline 1 & Eksperimen & 0,78 & \\
\hline 2 & k-epsilon Standard & 0,80 & 2,82 \\
\hline 3 & k-epsilon realizable & 0,77 & $-1,28$ \\
\hline 4 & k-epsilon $R N G$ & 0,76 & $-2,82$ \\
\hline 5 & k-omega Standard & 0,77 & $-1,28$ \\
\hline 6 & k-omega SST & 0,76 & $-2,31$ \\
\hline
\end{tabular}

Model viskos k-epsilon Realizable dan k-omega Standard memiliki nilai error paling kecil yaitu $1,28 \%$ yang mana nilai Koefisien Drag $\left(\mathrm{C}_{\mathrm{D}}\right)$ sebesar 0,77. Menurut Tuakia (2008) Model k-epsilon memiliki tingkat kestabilan, ekonomis (dari segi komputasi) dan akurasi yang cukup memadai serta sering digunakan dalam simulasi fluida. Kelebihan lain dari model viskos k-epsilon Realizable yaitu memiliki performa yang baik untuk aliran yang melibatkan putaran, lapisan batas yang memiliki gradient tekanan yang besar, separasi, dan resirkulasi. Maka model viskos yang tepat dalam simulasi CFD adalah $k$-epsilon Realizable.

\section{2) Grafik Pressure Coefficient $C_{P}$}

Berdasarkan grafik Koefisien Pressure $\left(\mathrm{C}_{\mathrm{P}}\right)$ menunjukkan tren yang relatif sama antara penelitian eksperimen dan simulasi CFD kelima model viscous $k$-epsilon standard, $k$ epsilon Realizable, k-epsilon RNG, k-omega standard, dan $k$ omega SST.

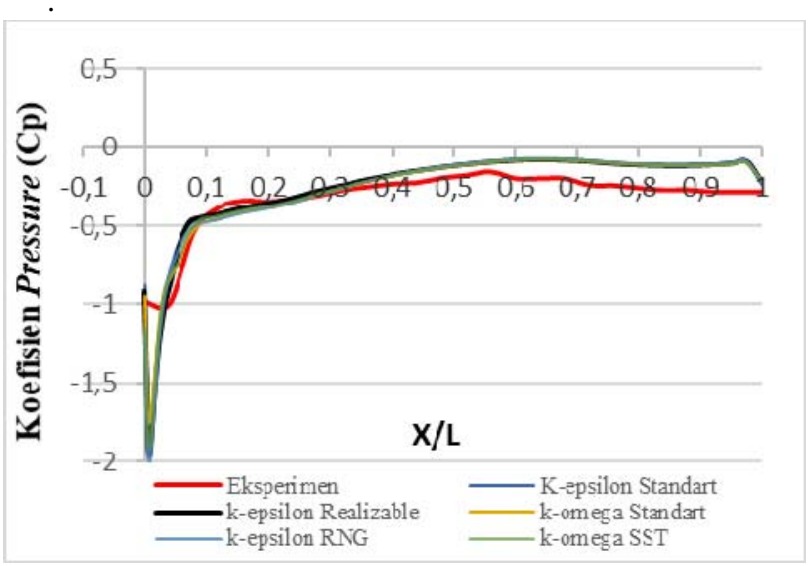

Gbr. 5 Grafik Koefisien Pressure $\left(C_{P}\right)$ Lower Surface pada Re 7,15 x $10^{4}$.

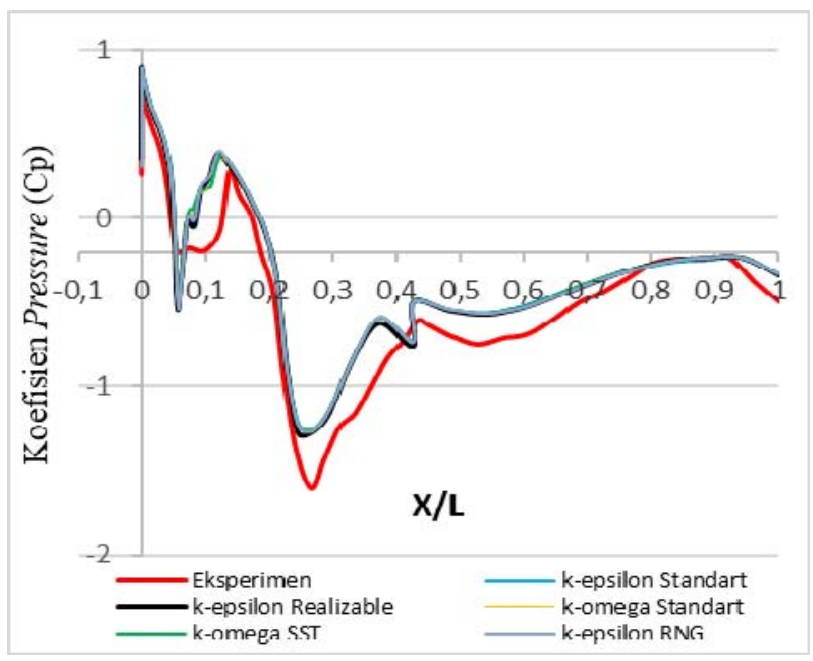

Gbr. 6 Grafik Koefisien Pressure $\left(\mathrm{C}_{\mathrm{P}}\right)$ Upper Surface pada Re 7,15 x $10^{4}$.

3) Grid Independency Test

Tabel III

Validasi Model Viskos

\begin{tabular}{|l|l|l|l|l|}
\hline No & Elements & Jumlah Nodes & $\mathbf{C}_{\mathbf{D}}$ & Error \\
\hline 1 & 213869 & 57361 & 0,77 & $1,28 \%$ \\
\hline 2 & 230454 & 60339 & 0,75 & $3,84 \%$ \\
\hline 3 & 253879 & 64743 & 0,69 & $11,53 \%$ \\
\hline 4 & 333551 & 79671 & 0,65 & $16,56 \%$ \\
\hline
\end{tabular}

Dari tabel 2 dilakukan pengujian grid untuk mencari komposisi jumlah nodes serta elements yang paling tepat dalam proses iterasi. Komposisi grid terbaik dimana persentase error $1,28 \%$ dengan nilai $C_{D} 0,78$ adalah grid pertama. 


\section{B. Hasil Penelitian}

1) Velocity Contour Pada Re 3,91 × $10^{6}$

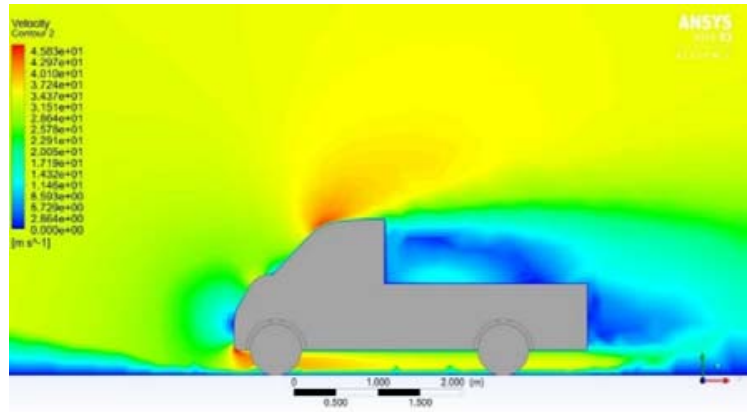

Gbr. 7 Velocity Contour Model Pick Up Standard dengan Rasio Panjang

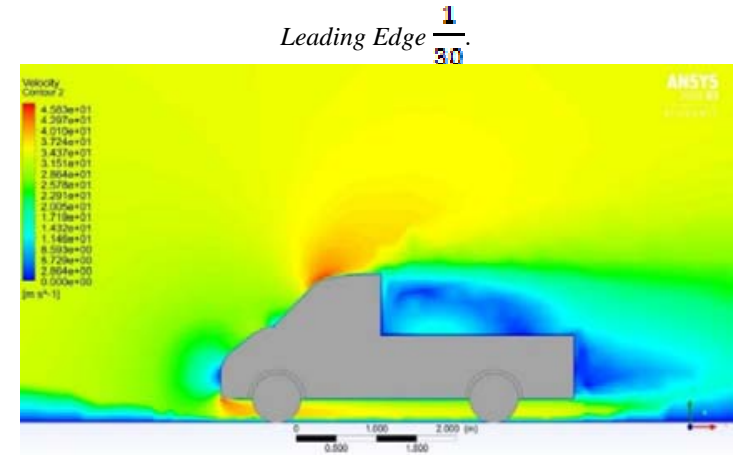

Gbr. 8 Velocity Contour Model Pick Up dengan Rasio Panjang Leading Edge $\frac{1}{13}$.

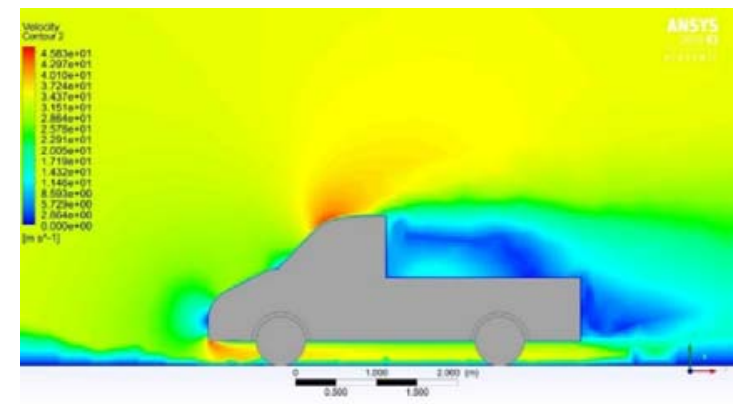

Gbr 9 Velocity Contour Model Pick Up dengan Rasio Panjang Leading Edge $\frac{1}{9}$.

Terlihat dengan pemvariasian rasio panjang leading edge dapat mempengaruhi kecepatan aliran yang melewati kontur bodi. Terdapat area berwarna biru di belakang kendaraan yang mana pada daerah tersebut terjadi defisit kecepatan aliran. Variasi yang memiliki luasan terkecil di daerah tersebut adalah variasi ketiga $\left(\frac{1}{9}\right)$ yang berarti defisit kecepatanya paling kecil.

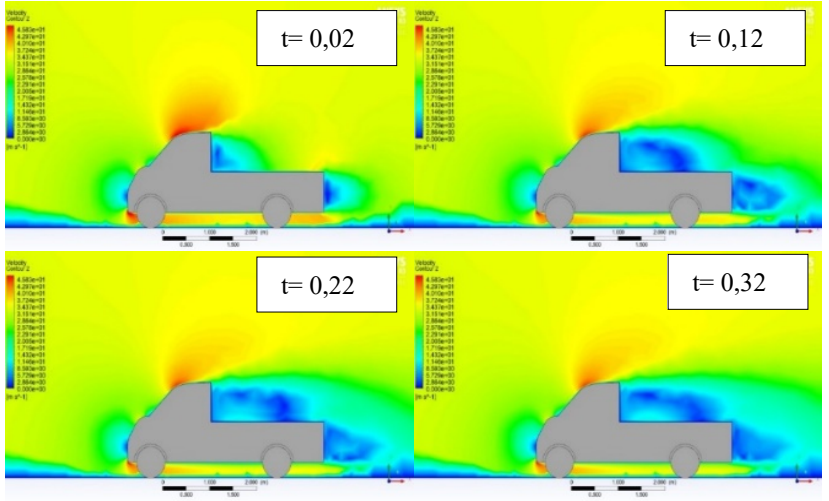

Gbr. 10 Velocity Contour Model Pick Up dengan Rasio Panjang Leading Edge $\frac{1}{30}$ Kondisi Unsteady.

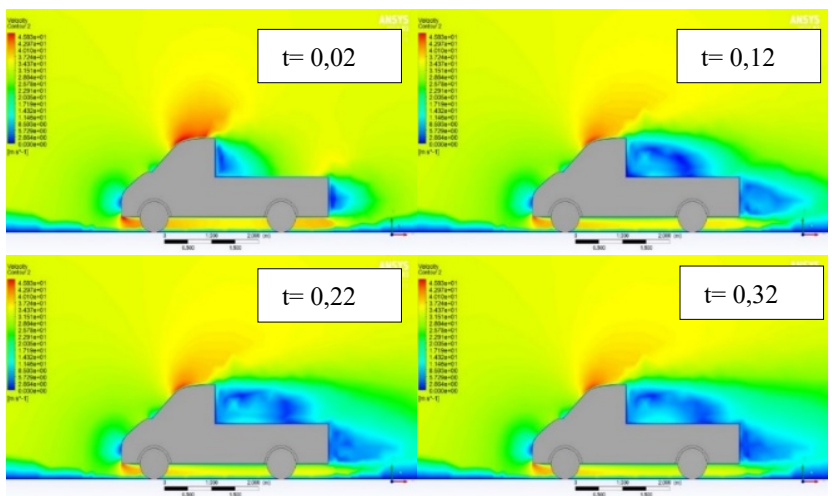

Gbr. 11 Velocity Contour Model Pick Up dengan Rasio Panjang Leading Edge $\frac{1}{13}$ Kondisi Unsteady.

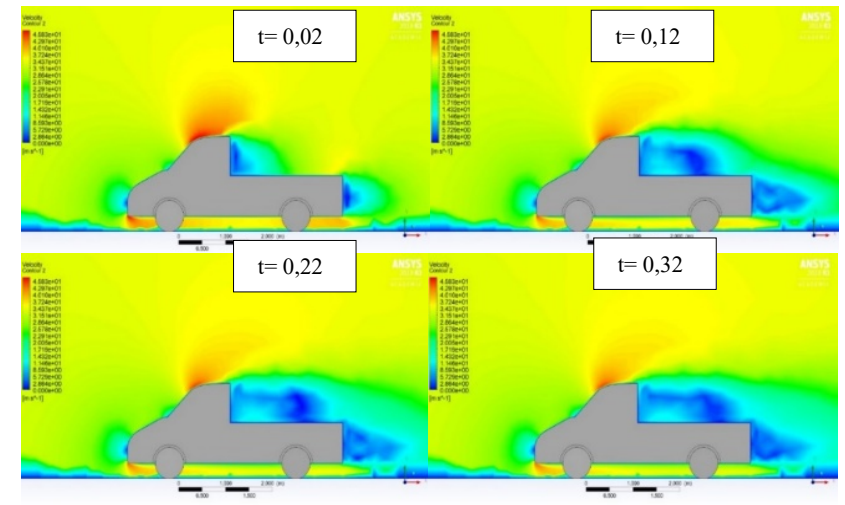

Gbr. 12 Velocity Contour Model Pick Up dengan Rasio Panjang Leading

$$
\text { Edge } \frac{1}{9} \text { Kondisi Unsteady. }
$$

Perkembangan kontur kecepatan ketiga variasi model pick up cenderung sama dimana perkembangan kontur kecepatan paling besar berada di 0,1 detik awal yaitu dari detik $0,02 \mathrm{ke}$ 0,12 . Pada 0,1 detik berikutnya perkembangan kontur kecepatan masih cukup terlihat namun tidak sebesar seperti 0,02 detik awal. 
2) Velocity Streamline Pada Re $3,91 \times 10^{6}$

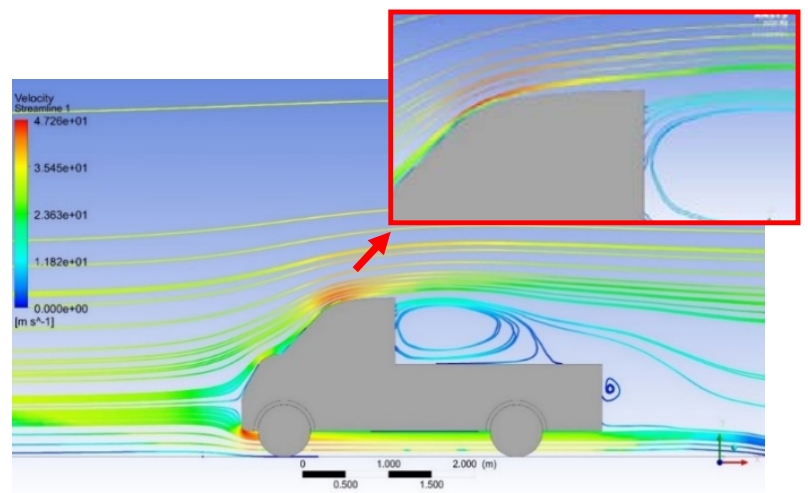

Gbr. 13 Velocity Streamline Model Pick Up Standard dengan Rasio Panjang Leading Edge $\frac{1}{30}$.

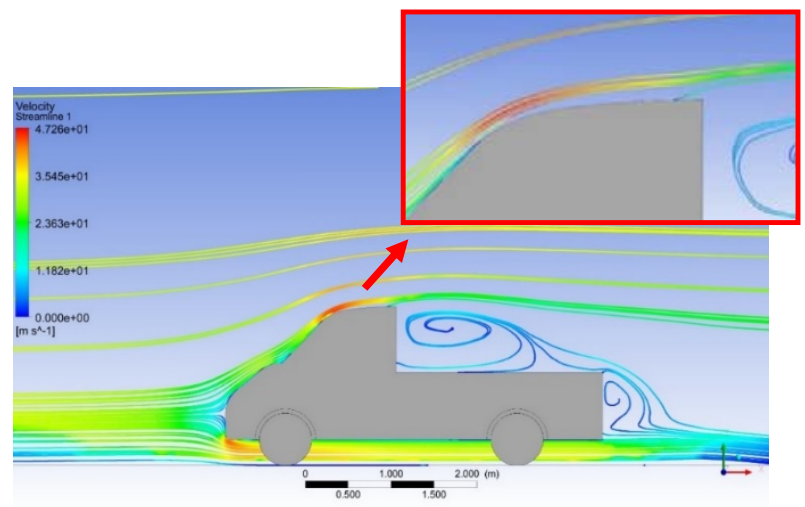

Gbr. 14 Velocity Streamline Model Pick Up dengan Rasio Panjang Leading Edge $\frac{1}{13}$.

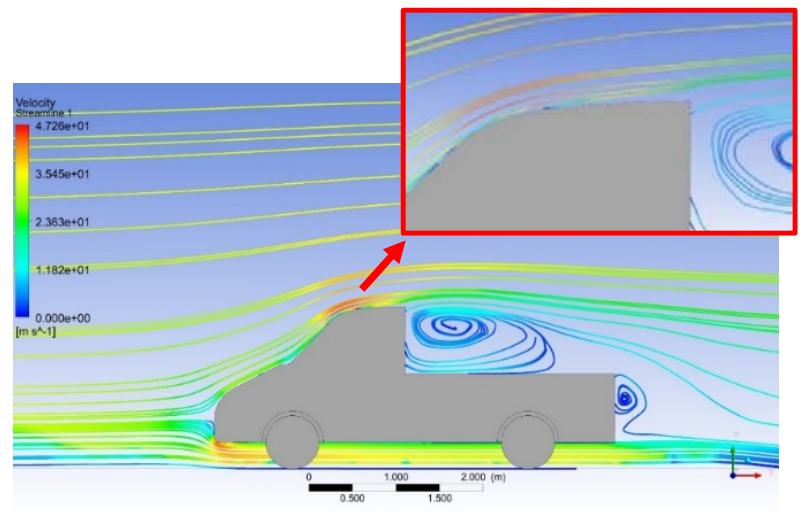

Gbr. 15 Velocity Streamline Model Pick Up dengan Rasio Panjang Leading Edge $\frac{1}{9}$.

Dari ketiga variasi rasio panjang leading edge, terjadinya separasi paling awal adalah pada model pick up standard, disusul variasi kedua dan variasi ketiga. Separasi di daerah atap kendaraan terjadi karena momentum aliran tidak mampu menahan tegangan geser di daerah tersebut. Pada gambar 15 terlihat jika terjadinya separasi tertunda atau lebih mundur paling jauh. Penundaan separasi menjadi sangat menguntungkan karena akan mempengaruhi fenomena yang terjadi di belakang model pick up.

Apabila ditinjau dari velocity streamline variasi yang memiliki daerah wake paling kecil adalah variasi ketiga (

Sehingga variasi ketiga merupakan variasi yang memiliki nilai Koefisien Drag $\left(\mathrm{C}_{\mathrm{D}}\right)$ paling kecil.

Berikut ini disajikan gambar hasil simulasi pada kondisi unsteady di sekitar bodi kendaraan. Fluktuasi velocity streamline dari awal akan diperlihatkan hingga mencapai kondisi steady. Terbentuk vortex di bagian bak dan belakang kendaraan. Vortex pada tiap timestep berkembang secara bertahap dari timestep 0,02 detik sampai 0,32 detik. Perkembangan pola streamline di atas ketiga variasi model pick up cenderung sama dimana pola streamline di 0,1 detik awal pola aliran masih dapat mengikuti kontur bodi dimana vortex di bak serta belakang kendaraan belum terbentuk yaitu pada detik 0,02 ke 0,12 . Pada 0,1 detik berikutnya vortex sudah mulai terbentuk dari dasar bak model pick up menyebabkan streamline di atas kendaraan mulai menjauh.

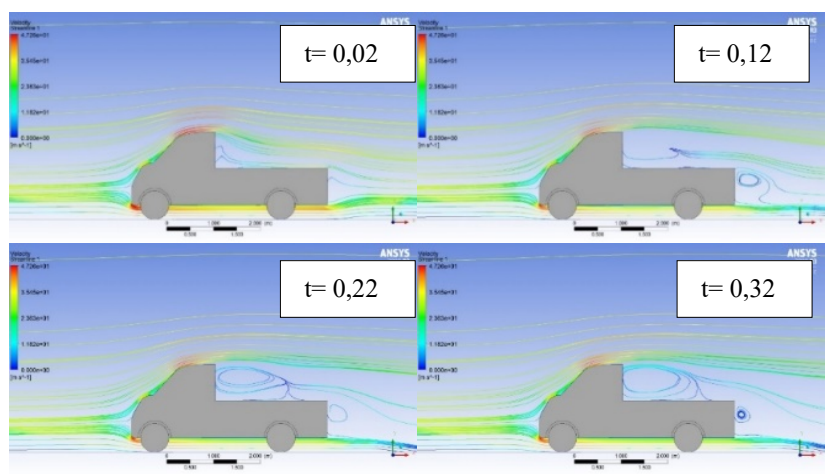

Gbr. 16 Velocity Streamline Model Pick Up dengan Rasio Panjang Leading Edge $\frac{1}{30}$ Kondisi Unsteady.
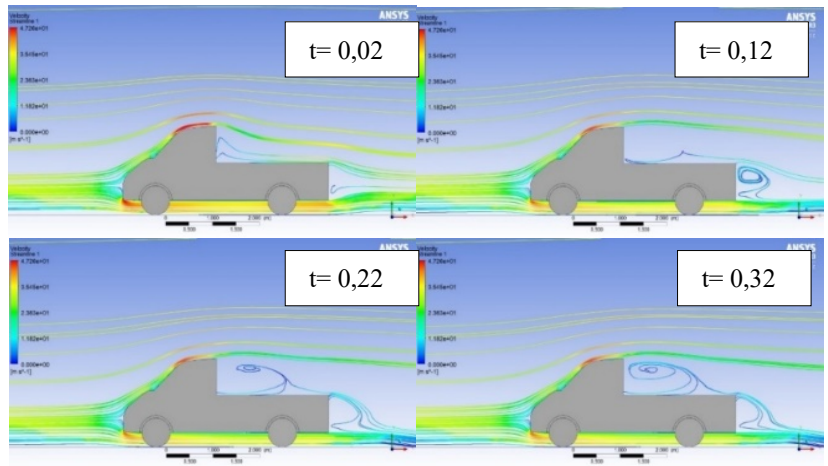

Gbr. 17 Velocity Streamline Model Pick Up dengan Rasio Panjang Leading Edge $\frac{1}{2 \cdot 2}$ Kondisi Unsteady. 


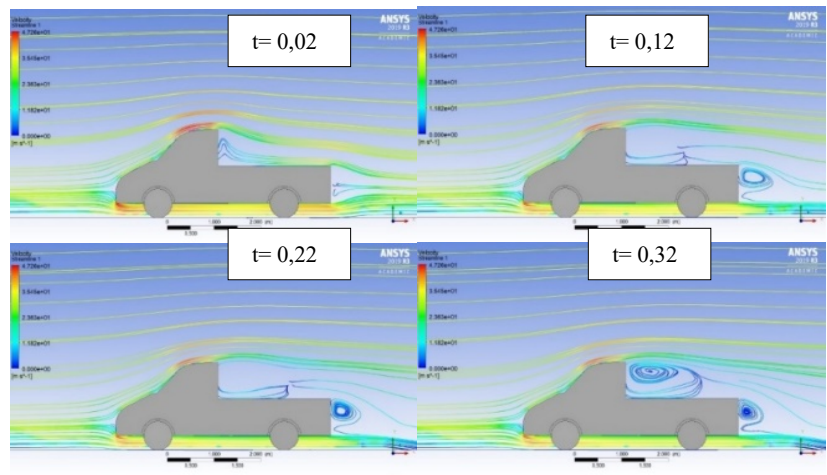

Gbr. 18 Velocity Streamline Model Pick Up dengan Rasio Panjang Leading Edge $\frac{1}{9}$ Kondisi Unsteady.

3) Pressure Contour Pada Re 3,91 × $10^{6}$

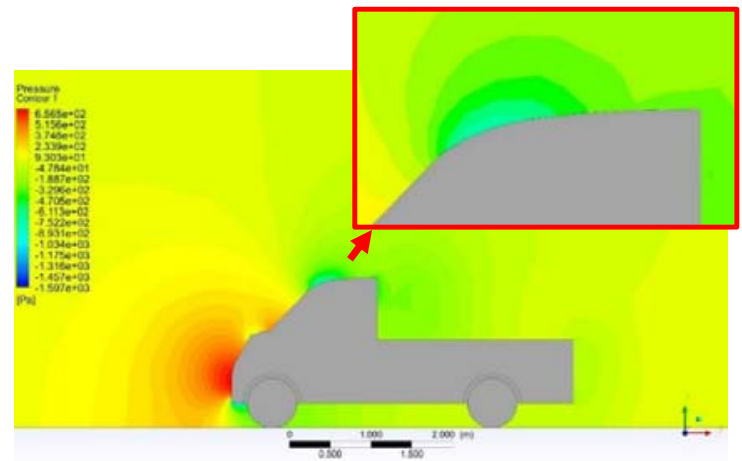

Gbr. 19 Pressure Contour Model Pick Up Standard dengan Rasio Panjang

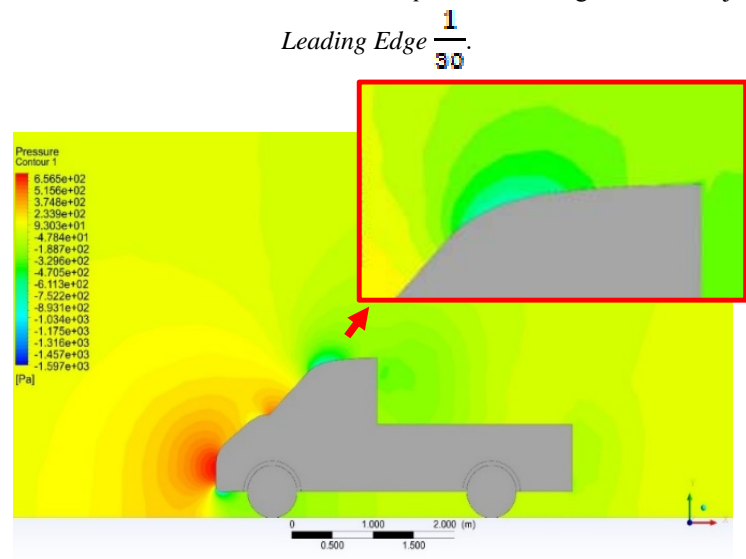

Gbr. 20 Pressure Contour Model Pick Up dengan Rasio Panjang Leading Edge $\frac{1}{13}$

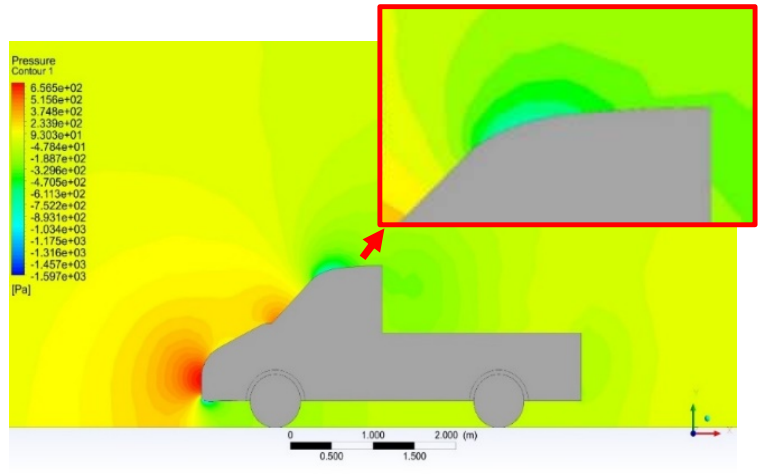

Gbr. 21 Pressure Contour Model Pick Up dengan Rasio Panjang Leading Edge $\frac{1}{9}$.

Pada bagian upper surface, terdapat daerah berwarna biru menunjukkan pada daerah tersebut terjadi bubble separation. Variasi yang memilliki daerah bubble separation paling lebar adalah variasi ketiga $\left(\frac{1}{9}\right)$. Sedangkan variasi dengan daerah bubble separation paling kecil adalah variasi standard dengan rasio $\frac{1}{30}$. Pola aliran di bagian depan kendaraan juga akan mempengaruhi luasan wake yang terbentuk di belakang kendaraan.

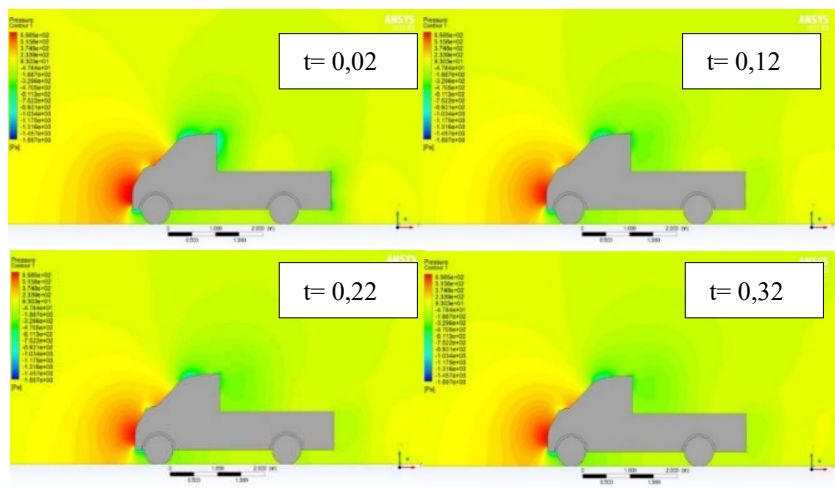

Gbr. 22 Pressure Contour Model Pick Up dengan Rasio Panjang Leading Edge $\frac{1}{30}$ Kondisi Unsteady.

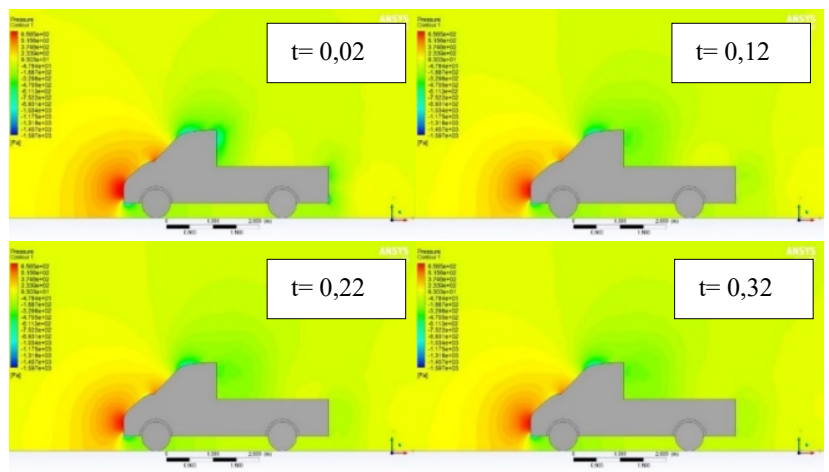

Gbr. 23 Pressure Contour Model Pick Up dengan Rasio Panjang Leading Edge $\frac{1}{13}$ Kondisi Unsteady. 


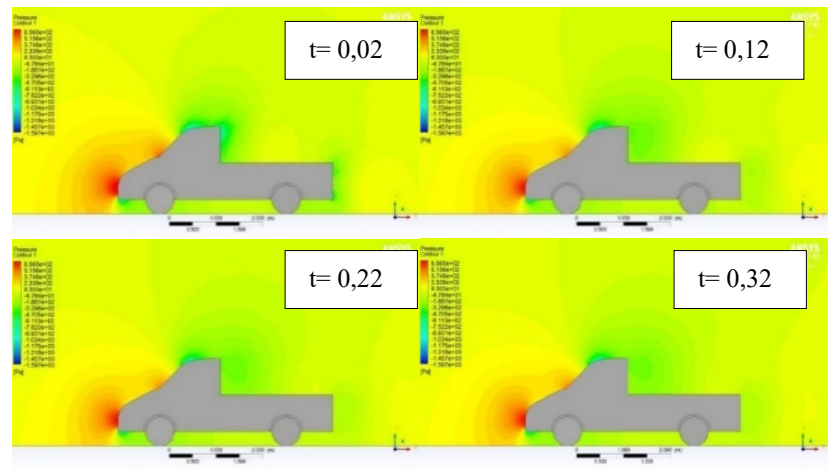

Gbr. 24 Pressure Contour Model Pick Up dengan Rasio Panjang Leading Edge $\frac{1}{9}$ Kondisi Unsteady.

Perkembangan kontur tekanan ketiga variasi model pick up cenderung sama dimana perubahan kontur tekanan paling mencolok berada di 0,1 detik awal yaitu dari detik 0,02 ke 0,12 . Dimana terdapat warna biru pada awalnya yang berarti bertekanan rendah di belakang atap kendaraan kemudian menghilang pada detik ke 0,12 . Pada 0,1 detik berikutnya, warna biru di belakang atap sudah berubah menjadi hijau dan tidak ada perubahan lain karena aliran hampir mencapai kondisi Steady.

4) Data Coefficient Lift $\left(C_{L}\right)$ dan Coefficient Drag $\left(C_{D}\right)$

Berikut ini adalah data $C_{L}$ dan $C_{D}$ yang diwujudkan dalam bentuk tabel dan grafik untuk melihat perubahan yang terjadi pada model kendaraan tiap variasi rasio leading edge berdasarkan variasi Reynolds Number.

Tabel IIIII

Karakteristik Aerodinamika pada Re $7,15 \times 10^{4}$

\begin{tabular}{|l|l|l|l|l|l|}
\hline \multirow{2}{*}{ No } & \multirow{2}{*}{ Variasi } & \multirow{2}{*}{$\mathrm{C}_{\mathrm{D}}$} & \multirow{2}{*}{$\mathrm{C}_{\mathrm{L}}$} & \multicolumn{2}{|l|}{ Persentase $\%$} \\
\cline { 5 - 6 } & & & & $\mathrm{CD}$ & $\mathrm{CL}$ \\
\hline 1 & Rasio Leading edge $\frac{i}{3}$ & 0,77 & 0,08 & 0 & 0 \\
\hline 2 & Rasio Leading edge $\frac{i}{i 2}$ & 0,76 & 0,05 & $1,2 \%$ & $37,5 \%$ \\
\hline 3 & Rasio Leading edge $\frac{i}{4}$ & 0,75 & 0,05 & $2,5 \%$ & $37,5 \%$ \\
\hline
\end{tabular}

Tabel IVV

Karakteristik Aerodinamika pada Re 2,6 x $10^{6}$

\begin{tabular}{|l|l|l|l|l|l|}
\hline \multirow{2}{*}{ No } & \multirow{2}{*}{ Variasi } & \multirow{2}{*}{$\mathrm{C}_{\mathrm{D}}$} & \multirow{2}{*}{$\mathrm{C}_{\mathrm{L}}$} & \multicolumn{2}{|l|}{ Persentase $\%$} \\
\cline { 5 - 6 } & & & & $\mathrm{C}_{\mathrm{D}}$ & $\mathrm{C}_{\mathrm{L}}$ \\
\hline 1 & Rasio Leading edge $\frac{1}{-}$ & 0,75 & 0,11 & 0 & 0 \\
\hline 2 & Rasio Leading edge $\frac{1}{-1}$ & 0,74 & 0,07 & $1,3 \%$ & $36,36 \%$ \\
\hline 3 & Rasio Leading edge - & 0,72 & 0,07 & $4 \%$ & $36,36 \%$ \\
\hline
\end{tabular}

Tabel V

Karakteristik Aerodinamika pada $\operatorname{Re} 3,26 \times 10^{6}$

\begin{tabular}{|l|l|l|l|l|l|}
\hline \multirow{2}{*}{ No } & \multirow{2}{*}{ Variasi } & \multirow{2}{*}{$\mathrm{C}_{\mathrm{D}}$} & \multirow{2}{*}{$\mathrm{C}_{\mathrm{L}}$} & \multicolumn{2}{|l|}{ Persentase $\%$} \\
\cline { 5 - 6 } & & & & $\mathrm{C}_{\mathrm{D}}$ & $\mathrm{C}_{\mathrm{L}}$ \\
\hline 1 & Rasio Leading edge $\frac{1}{-1}$ & 0,75 & 0,11 & 0 & 0 \\
\hline 2 & Rasio Leading edge $\frac{1}{1}$ & 0,74 & 0,07 & $1,3 \%$ & $36,36 \%$ \\
\hline 3 & Rasio Leading edge $\frac{1}{1}$ & 0,72 & 0,07 & $4 \%$ & $36,36 \%$ \\
\hline
\end{tabular}

Tabel VI

Karakteristik Aerodinamika pada Re 3,91 x $10^{6}$

\begin{tabular}{|l|l|l|l|l|l|}
\hline \multirow{2}{*}{ No } & \multirow{2}{*}{ Variasi } & \multirow{2}{*}{$\mathrm{C}_{\mathrm{D}}$} & \multirow{2}{*}{$\mathrm{C}_{\mathrm{L}}$} & \multicolumn{2}{|l|}{ Persentase $\%$} \\
\cline { 5 - 6 } & & & & $\mathrm{C}_{\mathrm{D}}$ & $\mathrm{C}_{\mathrm{L}}$ \\
\hline 1 & Rasio Leading edge $\frac{\mathrm{i}}{\mathrm{n}}$ & 0,75 & 0,11 & 0 & 0 \\
\hline 2 & Rasio Leading edge $\frac{1}{\mathrm{a}}$ & 0,74 & 0,07 & $1,3 \%$ & $36,36 \%$ \\
\hline 3 & Rasio Leading edge $\frac{1}{-}$ & 0,72 & 0,07 & $4 \%$ & $36,36 \%$ \\
\hline
\end{tabular}

Koefisien Drag $\left(\mathrm{C}_{\mathrm{D}}\right)$ merupakan gaya hambat dengan arah aliran angin sejajar bodi kendaraan yang timbul karena aliran udara menabrak suatu benda dan terjadi tekanantekanan pada benda yang dilaluinya sesuai dengan kontur benda tersebut. Semakin besar nilai $C_{D}$ yang dihasilkan maka semakin besar hambatan yang harus diterima suatu benda saat melaju. Sehingga semakin kecil nilai $C_{D}$ yang di terima mobil pick up maka hambatan yang diterima saat berjalan juga semakin kecil yang berimbas pada efisiensi penggunaan bahan bakar.

Dari data pada tabel, dengan memvariasikan rasio panjang leading edge dapat menurunkan nilai $\mathrm{C}_{\mathrm{D}}$. Semakin besar variasi rasio panjang leading edge, maka semakin kecil nilai $\mathrm{C}_{\mathrm{D}}$ yang dihasilkan. Mobil Pick up dengan Re 3,91 x $10^{6}$ yaitu pada kecepatan paling tinggi nilai $C_{D}$ mengalami penurunan sebesar $4 \%$ dari variasi standard ke variasi ketiga $\left(\frac{1}{g}\right)$.

Berikut ini adalah Koefisien Drag $\left(\mathrm{C}_{\mathrm{D}}\right)$ yang disajikan kedalam bentuk grafik untuk melihat penurunan yang terjadi pada Mobil Pick up.

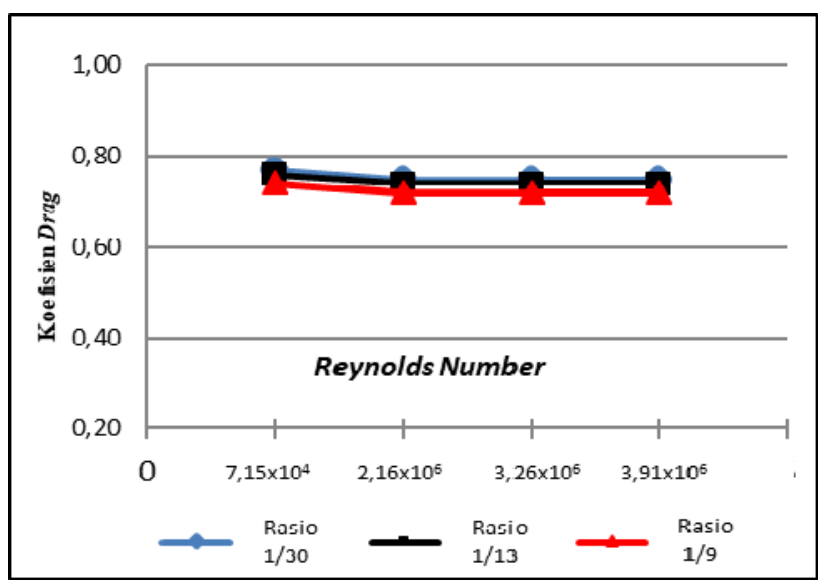

Gbr. 25 Grafik Nilai Koefisien $\operatorname{Drag}\left(\mathrm{C}_{\mathrm{D}}\right)$ 
Koefisien Lift $\left(\mathrm{C}_{\mathrm{L}}\right)$ merupakan gaya yang tegak lurus dengan arah aliran angin. Gaya ini disebut juga dengan gaya angkat, ini terjadi pada sebuah kendaraan karena perbedaan distribusi tekanan antara permukaan atas dengan permukaan bawah kendaraan. Semakin kecil $\mathrm{C}_{\mathrm{L}}$ maka stabilitas mobil akan mudah dicapai. Dilihat dari Tabel 6 Karakteristik Aerodinamika pada $\operatorname{Re} 3,91 \times 10^{6}$ yaitu pada kecepatan tinggi nilai $C_{L}$ mengalami penurunan sebesar $36,36 \%$ dari variasi standard ke variasi ketiga $\left(\frac{1}{9}\right)$.

Berikut ini adalah Koefisien Lift $\left(\mathrm{C}_{\mathrm{L}}\right)$ yang disajikan kedalam bentuk grafik untuk melihat penurunan yang terjadi pada Mobil Pick up.

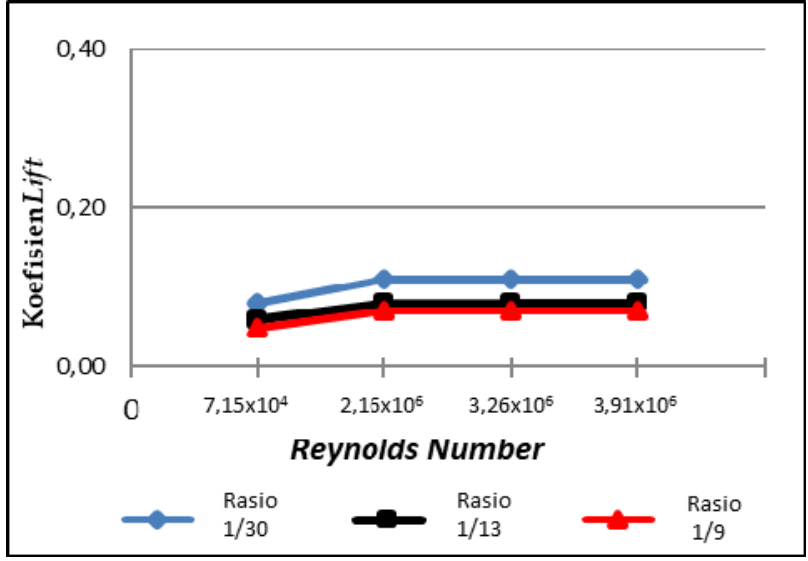

Gbr. 26 Grafik Nilai Koefisien Lift $\left(\mathrm{C}_{\mathrm{L}}\right)$

Dengan mempertimbangkan efisiensi gaya aerodinamika pada model mobil pick up dan tujuan utama dari penelitian adalah untuk bisa menurunkan nilai $C_{D}$ supaya hambatan pada kendaraan angkutan pick up semakin kecil serta nilai $\mathrm{C}_{\mathrm{L}}$ yang juga kecil, maka dipilih variasi rasio panjang leading edge $\frac{1}{9}$. Variasi tersebut memiliki penurunan nilai $C_{D}$ terbaik serta nilai $\mathrm{C}_{\mathrm{L}}$ yang kecil. Model pick up dengan variasi rasio $\frac{1}{9}$ dipilih sebagai variasi terbaik dengan nilai $C_{D} 0,72$ yang mengalami penurunan sebesar 0,03 dengan persentase penurunan $4 \%$ dan nilai $C_{L}$ sebesar 0,07 yang mengalami penurunan 0,04 dengan persentase $36,36 \%$ pada $\operatorname{Re} 3,91 \times 10^{6}$.

\section{KESIMPULAN}

Dari analisa hasil simulasi CFD mengenai pengaruh variasi rasio panjang leading edge terhadap gaya aerodinamika pada model kendaraan pick up, diperoleh beberapa kesimpulan berikut:

1. Berdasarkan velocity contour semakin besar variasi rasio panjang leading edge, maka defisit kecepatan dibelakang kendaraan semakin kecil. Berdasarkan velocity streamline, dengan memodifkasi rasio panjang leading edge dapat memperbaiki laju aliran angin yang mengenai bodi depan kendaraan menjadi lebih aerodinamis. Pada variasi rasio paling besar dapat meningkatkan distribusi momentum di atas kendaraan, yang membuat aliran lebih mengikuti kontur bodi sehingga separasi tertunda atau bergeser kebelakang. Berdasarkan pressure contour variasi rasio panjang leading edge, variasi rasio paling besar memiliki bubble separation di atas kendaraan paling lebar. Jadi variasi rasio panjang leading edge mobil pick up paling besar $\left(\frac{1}{-}\right)$ memiliki performa aerodinamika paling baik.

2. Pemvariasian rasio panjang leading edge cenderung menurunkan nilai Koefisien Drag $\left(\mathrm{C}_{\mathrm{D}}\right)$. Penurunan Koefisien Drag $\left(\mathrm{C}_{\mathrm{D}}\right)$ terbaik adalah variasi panjang leading edge rasio $\frac{1}{9}$ pada $\operatorname{Re} 3,91 \times 10^{6}$ dengan persentase penurunan $4 \%$ dari model standard yakni sebesar 0,72 .

3. Pemvariasian rasio panjang leading edge cenderung menurunkan nilai Koefisien Lift $\left(\mathrm{C}_{\mathrm{L}}\right)$. Penurunan Koefisien Lift $\left(\mathrm{C}_{\mathrm{L}}\right)$ terbaik adalah variasi panjang leading edge rasio $\frac{1}{9}$ pada $\operatorname{Re} 3,91 \times 10^{6}$ dengan persentase penurunan sebesar $36,36 \%$ dibandingkan dengan model standard yakni sebesar 0,07 .

4. Variasi panjang leading edge dengan rasio $\frac{1}{9}$ memiliki nilai Koefisien Drag $\left(\mathrm{C}_{\mathrm{D}}\right)$ serta Koefisien Lift $\left(\mathrm{C}_{\mathrm{L}}\right)$ paling kecil dari kedua variasi lain. Sehingga leading edge dengan rasio $\frac{1}{9}$ dipilih sebagai variasi terbaik, karena memiliki penurunan nilai Koefisien Drag $\left(\mathrm{C}_{\mathrm{D}}\right)$ paling besar.

5. Pemvariasian rasio panjang leading edge akan menunda terjadinya separasi di bagian upper surface kendaraan. Terjadinya separasi paling jauh adalah variasi panjang leading edge dengan rasio $\frac{1}{9}$ pada $\operatorname{Re} 3,91 \times 10^{6}$.

\section{REFERENSI}

[1] Barnard, R. H. (2009). Road Vehicle Aerodyamic Design. Third Edition. Hertfordshire: MechAero Publishing.

[2] Fox, Robert W. and Mc. Donald, Alan T. 2003. Introduction to Fluid Mechanics 6th Edition. New York: John Wiley \& Sons, Inc.

[3] Hucho, Wolf-Heinrich, and Sovran, G. 1993. Aerodynamics of Road Vehicles. Annual Review of Fluid Mechanics. Vol. 25(1), pp485-537.

[4] Katz, Joseph. 2006. Aerodynamics of Race Car. San Diego: Department of Aerospace Engineering, San Diego State University.

[5] Mustafa, Ahmad Endra. 2018. Simulasi Numerik Variasi Leading Edge Terhadap Karakteristik Aerodinamika Bodi Bus. Jurnal Pendidikan Teknik Mesin. Volume 07 Nomor 03 Tahun 2018. 109-116.

[6] Nevers, Noel de, 1991. Fluid Mechanics for Chemical Engineers. 2nd Edition. New York: Mc Graw Hill.

[7] Surya, P. B. 2014. Pengaruh Variasi screen terhadap Intensitas Turbulensi Wind Tunnel Tipe Open Circuit Subsonic di Jurusan Teknik Mesin UNESA. Jurnal Teknik Mesin. Volume 03 Nomor 02: 29-37. Surabaya: Universitas Negeri Surabaya.

[8] Sutantra, I Nyoman. 2010. Teknologi Otomoitif Teori dan Aplikasinya. Edisi Kedua. Surabaya: Guna Widya Press.

[9] Tuakia, Firman. 2008. Dasar-Dasar CFD Menggunakan FLUENT. Bandung: Informatika.

[10] Wailanduw. A. G. 2005. Studi Karakteristik Aliran Pada Kendaraan Jenis Van yang Menggunakan Side Airdams. JURNAL TEKNIKA Fakultas Teknik UNESA. Vol. 6 No. 2, Agustus 2005: 130 - 141.

[11] Young, Donald F., Bruce R. Munson, Theodore H. Okiishi, Wade B. Huebsch. 2011. A Brief Introduction to Fluid Mechanics.5th Edition. New York: John Wiley \& Sons, Inc. 